\title{
Disease Notes
}

\section{Diseases Caused by Fungi and Fungus-Like Organisms}

First Report of Powdery Mildew Caused by Podosphaera fusca on Helianthus tuberosus in China

\section{L. Pei, ${ }^{\dagger}$ Q. C. Zhang, Y. Y. Guo, X. Y. Wang, and Z. Yu}

Henan Provincial Engineering Research Center for Development and Application of Characteristic Microorganism Resources, Key Laboratory of Plant-Microbe Interactions, Department of Life Science, Shangqiu Normal University, Shangqiu 476000, China

Funding: Funding was provided by Henan Province programs for Science and Technology Development (182102110330) and Henan Province Natural Science Foundation (182300410058). Plant Dis. 105:709, 2021; published online as https://doi.org/10.1094/PDIS-07-20-1488-PDN. Accepted for publication 22 September 2020.

Helianthus tuberosus L. (Jerusalem artichoke) is an herbaceous perennial plant in the Asteraceae that is native to North America but introduced to China in the 17th century. The tubers of H. tuberosus are used as a vegetable, for the pharmaceutical production of inulin, and as a source of ethanol biofuel, several B vitamins, and minerals. From June to September 2009, severe powdery mildew infection was observed on $H$. tuberosus in a vegetable garden at Shangqiu Normal University, Shangqiu, China. Approximately $60 \%$ of leaves on individual plants were symptomatic, and almost $70 \%$ of the plants were infected. Initially, discrete powdery mildew colonies appeared on the upper surface of the leaves and on stems of the plants. Later, mycelial growth was amphigenous, thick, forming irregular white patches, covering the whole leaf surface. Eventually, leaves turned yellow, withered, and abscissed. Microscopic observations showed that conidia on infected leaves were ellipsoid-ovoid to barrel-shaped, with distinct fibrosin bodies visible in their cytoplasm, measuring 28 to $38 \times 15$ to $22 \mu \mathrm{m}(n=40)$. Conidiophores were unbranched, straight, 80 to $210 \times 8$ to $14 \mu \mathrm{m}(n=40)$ in size, and produced two to six immature conidia in chains with intercellular diaphragms. Foot cells of conidiophores were cylindrical and 45 to $65 \times 8$ to $14 \mu \mathrm{m}(n=40)$, with slight constrictions at basal septa, and followed by one to three short cells. Fungal hyphae were septate, branched, and flexuous to straight, and 5 to $8 \mu \mathrm{m}$ wide with indistinct to slightly nipple-shaped appressoria. These structures are typical of the genus Podosphaera, although chasmothecia were not observed. The sequence of ITS1-5.8s-ITS2 region of rDNA was amplified from conidia collected from infected leaves with universal primers ITS1F and ITS4 (White et al. 1990), sequenced, and analyzed using the BLASTn search of GenBank. Amplicons were 603 bp (GQ927254) and exhibited $99.83 \%$ sequence identity with the sequence of $P$. fusca from Cucurbita pepo (KJ698669) in Italy (Pirondi et al. 2015). The fungal species was identified as $P$. fusca (synonym $P$. xanthii) by morphological characteristics and molecular analysis (Braun and Cook 2012; Braun and Takamatsu 2000). Pathogenicity tests were conducted by gently pressing the infected leaves onto leaves of six healthy $H$. tuberosus plants, and six noninoculated plants served as controls. Plants were maintained in a greenhouse at $25 \pm 2^{\circ} \mathrm{C}$. Eight days after inoculation, symptoms similar to those observed under natural conditions developed on the inoculated leaves of $H$. tuberosus plants, whereas the control plants remained symptomless. The fungus on inoculated leaves was morphologically identical to that first observed in the field. $P$. fusca parasitizes a large number of asteraceous species including Euryops pectinatus (Saenz et al. 2000), Coreopsis lanceolata (Garibaldi et al. 2007), Cosmos caudatus (Siddiqui et al. 2011), Herba eupatorii (Ding et al. 2013), and so on. Powdery mildew caused by $P$. fusca has been reported on H. tuberosus in Russia (Farr and Rossman 2019). Golovinomyces ambrosiae was previously recorded on $H$. tuberosus in China (Huang et al. 2017; Radisek et al. 2018). This is the first report to our knowledge of powdery mildew $P$. fusca on $H$. tuberosus in China. It could cause significant yield losses and become a threat to production of $H$. tuberosus.

References:

Braun, U., and Cook, R. T. A. 2012. Taxonomic Manual of the Erysiphales (Powdery Mildews). CBS Biodiversity Series 11. CBS-KNAW Fungal Biodiversity Centre, Utrecht, the Netherlands.

Braun, U., and Takamatsu, S. 2000. Schlechtendalia (Halle) 4:1.

Ding, J. P., et al. 2013. Plant Dis. 97:995.

Farr, D. F., and Rossman, A. Y. 2019. Fungal Databases, Syst. Mycol. Microbiol. Lab., ARS, USDA. https://nt.ars-grin.gov/fungaldatabases/.

Garibaldi, A., et al. 2007. Plant Dis. 91:1203.

Huang, J. G., et al. 2017. Plant Dis. 101:1317.

Pirondi, A., et al. 2015. Fungal Biol. 119:791.

Radisek, S., et al. 2018. J. Plant Pathol. 100:331.

Saenz, G. S., et al. 2000. Plant Dis. 84:1048.

Siddiqui, Y., et al. 2011. Plant Dis. 95:495.

White, T. J., et al. 1990. Page 315 in: PCR Protocols: A Guide to Methods and

Applications. Academic Press, San Diego, CA.

The author(s) declare no conflict of interest.

e-Xtra

Keywords: fungi, ornamentals, herbaceous/flowering plants, pathogen detection

${ }^{\dagger}$ Indicates the corresponding author.

E-mail: D. L. Pei; peidongli@126.com 